AFP... song không phân loại được nguyên nhân gây bệnh.

\section{KẾT LUẬN}

Các bệnh gan chuyển hóa là các nguyên nhân có thể gầy tồn thương gan dưới cả hai dạng cấp tính và mạn tính. Bệnh không chỉ gây ảnh hưởng tới các trẻ bị bệnh trong thời kỳ thơ ấu mà còn gây hậu quả ở tuổi trưởng thành. Các bệnh gan chuyển hoá có những kiểu hình khá đa dạng như bệnh gan mạn ở các bệnh nhân Wilson, NICCD, Glycogenose, PFIC, Alagille...hay cấp tính với hậu quả nặng nề như suy gan tối cấp ở bệnh nhẩn Wilson, CTLN2... Việc chẩn đoán xác định các bệnh nhân có bệnh gan chuyển hoá không chỉ có ý nghĩa điều trị và cứu sống bệnh nhi ở tuổi thơ ấu mà còn giúp quản lý tình trạng bệnh, kiểm soát triệu chứng, biến chứng của bệnh đảm bảo ổn định chất lượng cuộc sống của bệnh nhân không chỉ trong thời kỳ̀ thơ ấu mà cả ở tuổi trưởng thành.
TÀl LIỆ THAM KHẢO

1. Kaur S, Kumar P, Kumar V, Sarin SK, Kumar A. Etiology and prognostic factors of acute liver failure in children. Indian Pediatr. 2013 vol 50 pages 677-689

2. Khanna $\mathbf{R}$, Alam $\mathbf{S}$, Sherwani $\mathbf{R}$, Arora $\mathbf{S}$, Arora NK, Malik A. Alpha-1 antitrypsin deficiency among Indian children with liver disorders. Indian J Gastroenterol. 2006; vol 25 pages191-193

3. Zhang $\mathbf{Z H}$, Lin $\mathbf{W X}$, Deng $\mathbf{M}$, et al. Clinical, molecular and func- tional investigation on an infant with neonatal intrahepatic cholestasis caused by citrin deficiency (NICCD). PLoS One. 2014 vol 9 pages 89267

4. European Association for Study of Liver. EASL clinical practice guidelines: Wilson's disease. J Hepatol. 2012 Vol 56 pages 671-685.

5. Arora NK, Arora S, Ahuja A, et al. Alpha 1 antitrypsin deficiency in children with chronic liver disease in North India. Indian Pediatr. 2010 vol 47, pages 1015-1023.

6. Keli Hansen, Simon Horslen et al. Metabolic liver disease in children (2008). Liver transplantation Vol 14, pages 713-733

\title{
ĐĂC ĐIỂM LÂM SÀNG, CÂN LÂM SÀNG VÀ MộT Số YẾU Tố LIÊN QUAN ĐẾN KẾT QUẢ ĐIỀU TRI BỆNH NHÂN SỐC NHIỄM KHUẨN TẠI BÊ̂NH VIỆN TRUNG ƯO'NG THÁI NGUYÊN
}

\section{TÓM TẮT}

Mục tiêu: Mô tả đặc điểm lâm sàng, cận lâm sàng và phẩn tích một số yểu tố liên quan đến kết quả điều trị bệnh nhân sốc nhiê̂m khuẩn. Đối tượng, phương pháp nghiên cứu: Nghiên cứu mô tả cắt ngang trên 47 bệnh nhânsốc nhiểm khuẩn. Kết quả: Tuổi trung bình của đối tượng nghiên cứu là $61,4 \pm 15,2$. Tuổi cao nhất là 92 và tuổi thấp nhất là 15 . Giới tính nam chiếm tỷ lệ cao hơn 76,6\%, nữ chỉ chiếm 23,4\%.Đa phần các bệnh nhân sốc nhiễm khuẩn có không có sốt hoặc sốt nhè. Sốt cao chỉ chiếm 23,4\%, trong khi đó tỉ lệ bệnh nhẩn không sốt chiếm cao nhất tới $61,7 \%$. Vị trí ổ nhiễm khuẩn tiên phát thường gặp chủ yếu là cơ quan hô hấp và tiêu hóa, trong đó hô hấp chiếm $44,7 \%$, tiêu hóa là $34 \%$. Kết quả nuôi cây vi khuẩn chỉ cho kết quả dương tính $17 \%$. Gía tri trung bình lactat máu của bệnh nhân sốc nhiếm khuẩn là $6,82 \pm 4,16$. Đa số bểnh nhân có gái trị lactat máu $>6 \mathrm{mmol} / \mathrm{l}$ chiếm tỉ lê $51,1 \%$. Có mối liên quan có ý nghĩa thống kê với đổ tin cậy $95 \%$ giữa tình trạng rối loạn đông máu, thở

${ }^{1}$ Trường Đại học Y dược Thái Nguyên

²Bệnh viện Trung ương Thái Nguyên

Chịu trách nhiệm chính: Nguyễn Thanh Thủy

Email: thanhthuyyk44@gmail.com

Ngày nhận bài: 21.10.2020

Ngày phản biên khoa hoc: 23.11.2020

Ngày duyệt bài: 8.12 .2020

\section{Nguyễn Thanh Thủy ${ }^{1}$, Phạm Kim Liên ${ }^{1,2}$}

máx xâm nhập và kết cục ra viện ở bệnh nhân sốc nhiếm khuẩn. Kết luận: Bệnh nhân tuổi càng cao càng có nguy cơ sốc nhiê̂m k̉huẩn cao hơn. Nam giới có tỉ lệ mắc bệnh cao hơn nữ giới. Ổ nhiễm khuẩn tiên phát thường gặp nhất là cơ quan hô hấp, tỉ lệ cây máu dương tính thấp. Có mối liên quan có ý nghĩa thống kê với độ tin cậy $95 \%$ giữa tình trạng rối loạn đông máu, thở máy xâm nhập và kết cục ra viện ở bệnh nhân sốc nhiễm khuẩn.

Ti̛ khóa: Lâm sàng, cận lâm sàng, yếu tố liên quan, sốc nhiễm khuẩn.

\section{SUMMARY \\ CLINICAL, SUBCLINICAL \\ CHARACTERISTICS ANH SOME FACTORS RELATE TO TREATMENT OUTCOME IN PATIENTS WITH SEPTIC SHOCK}

Objective: Describe clinical, subclinical characteristics and analysis some factors relate to treatment outcome in patients with septic shock. Methods: The descriptive study cut across 47 patients in septic shock. Results: Average age of study subjects is $61,4 \pm 15,2$. The highest age is 92 and the lowest one is 15 . Male sex accounts for $76,6 \%$ higher rate, female only $23,4 \%$. The majority of patients with septic shock have no fever or mild fever. High fever only accounted for $23,4 \%$, while the proportion of patients without fever was the highest at $61.7 \%$. Common primary sites of infection are 
respiratory and digestive organs, of which the respiratory tract accounts for $44,7 \%$, and digestion is $34 \%$. Bacterial culture results showed a positive result of only $17 \%$. The mean blood lactate value of patients with septic shock was $6,82 \pm 4,16$. The majority of patients with blood lactate values $>6 \mathrm{mmol} / \mathrm{l}$ accounts for $51,1 \%$. There was a statistically significant association with a 95\% confidence between coagulation disorder, invasive mechanical ventilation and treatment outcome in patients with septic shock. Conclusion: Older patients are at higher risk of septic shock, with higher rates of infection than women. The most common primary infection drive is the respiratory organs, with a low positive blood culture. There was a statistically significant association with a $95 \%$ confidence between coagulation disorder invasive mechanical ventilation and treatment outcome in patients with septic shock.

Keywords: Clinical, subclinical, factor relate, septic shock.

\section{I. ĐĂT VẤN ĐỀ}

Sốc nhiễm khuẩn là một bệnh cảnh nghiêm trọng, thường gặp tại các khoa Hồi Sức - Cấp Cứu, đồng thời cũ̃ng là nguyên nhân gây tử vong hàng đâu tại các khoa này. Tỉ lệ tử vong cao $40 \%-80 \%$.

Nhận biết nhanh, hồi sức sớm, kháng sinh kịp thời, loại bỏ ổ nhiễm khuẩn, phục hổi tình trạng huyết động sớm tại các khoa Hồi Sức - Cấp Cứu là ưu tiên hàng đầu góp phần giảm tỉ lệ tử vong. Tuy nhiên sốc nhiễm khuẩn là một bệnh cảnh đa dạng, phức tạp, dễ nhầm lẫn với các bệnh lý khác gây khó khăn trong việc chẩn đoán, điều trị sớm và cải thiện tiên lượng bệnh cho bệnh nhân.

Vì vậy tôi tiến hành nghiển cứu đề tài: "Đặc điểm lâm sàng, cận lâm sàng và một số yếu tố liên quan đến kết quả điều trị sốc nhiễm khuẩn tại bệnh viện Trung ương Thái Nguyên" với mục tiêu: Mô tả đặc điểm lâm sàng, cận lâm sàng và phân tích một số yêu tố liên quan đến kêt quả điều trị bệnh nhân sốc nhiễm khuẩn.

II. ĐốI TƯợNG VÀ PHƯƠNG PHÁP NGHIÊN CứU

Tiến hành nghiên cứu mô tả cắt ngang trên 47bệnh nhân sốc nhiễm khuẩn điều trị tạibệnh viện Trung ương Thái Nguyêntrong thời gian nghiên cứu từ tháng 7 năm 2019 đến tháng 7 năm 2020.

Các chỉ tiêu nghiên cứu:

- Đặc điểm chung: Tuổi, giới.

- Đặc điểm lâm sàng: Triệu chứng sốt, vị trí ổ nhiễm khuẩn tiên phát.

- Đặc điểm cận lâm sàng: Kết quả nuôi cấy vi khuẩn, lactat máu.

- Một số yếu tố liên quan đến kết quả điều trị: Rối loạn đông máu, thở máy xâm nhập.

Phương pháp thu thập số liệu: Khám lâm sàng, làm các xét nghiệm, điều trị theo phác đồ, thu thập số liệu

Xử lí số liệu: xử lí số liệu bằng phần mềm Spss 20.0

\section{KẾT QUẢ NGHIÊN CỨU}

Bảng 1. Đặc điểm chung của đôi tượng nghiên cứu

\begin{tabular}{|c|c|c|c|}
\hline \multicolumn{2}{|c|}{ Đăc điểm } & Số lượng & Tỉ lệ(\%) \\
\hline \multirow{4}{*}{ Tuổi } & $<40$ & 4 & 8.5 \\
\cline { 2 - 4 } & $40-54$ & 9 & 19.1 \\
\cline { 2 - 4 } & $55-69$ & 19 & 40.4 \\
\cline { 2 - 4 } & $\geq 70$ & 15 & 31.9 \\
\cline { 2 - 4 } & Tống & 47 & 100 \\
\cline { 2 - 4 } & $\overline{\mathrm{X}} \pm \mathrm{SD}$ & \multicolumn{2}{|c|}{$61.4 \pm 15.2$} \\
\cline { 2 - 4 } & Min - max & \multicolumn{2}{|c|}{$15-92$} \\
\hline \multirow{3}{*}{ Giới } & Nam & 36 & 76.6 \\
\cline { 2 - 4 } & Nữ & 11 & 23.4 \\
\cline { 2 - 4 } & Tống & $\mathbf{4 7}$ & $\mathbf{1 0 0}$ \\
\hline
\end{tabular}

Nhận xét: - Tuối trung bình của đối tượng nghiên cứu là $61,43 \pm 15,15$. Tuổi cao nhất là 92 và tuổi thấp nhất là 15 . Trong đó, nhóm tuổi 55-69 chiếm tỷ lệ cao nhất là 40,2\%.

- Giới tính nam chiếm tỷ lệ cao hơn $76,6 \%$, nữ chỉ chiếm $23,4 \%$.

Bảng 2. Đặc điểm sốt, ổ nhiễm khuẩn tiên phát

\begin{tabular}{|c|c|c|c|}
\hline \multicolumn{2}{|c|}{ Đặc điếm } & Số lượng & Tỷ lệ(\%) \\
\hline \multirow{2}{*}{$\begin{array}{c}\text { Ố } \\
\text { nhiễm } \\
\text { khuẩn }\end{array}$} & Hô hấp & 21 & 44.7 \\
\cline { 2 - 4 } tiên & Tiêu hóa & 16 & 34 \\
\cline { 2 - 4 } phát & Tiết niệu & 3 & 6.4 \\
\cline { 2 - 4 } & Khác & 7 & 14.9 \\
\cline { 2 - 4 } & Tống & $\mathbf{4 7}$ & $\mathbf{1 0 0}$ \\
\hline \multirow{3}{*}{$\begin{array}{c}\text { Mức } \\
\text { độ sốt }\end{array}$} & Không sốt & 29 & 61.7 \\
\cline { 2 - 4 } & Sốt nhe & 7 & 14.9 \\
\cline { 2 - 4 } & Sốt cao & 11 & 23.4 \\
\cline { 2 - 4 } & Tống & $\mathbf{4 7}$ & $\mathbf{1 0 0}$ \\
\hline
\end{tabular}

Nhân xét: - Vị trí ổ nhiếm khuẩn tiên phát thường gặp là ở cơ quan hô hấp hoặc tiêu hóa. Trong đó hô hấp chiếm 44,7 \%, tiêu hóa là 34\%.

- Tỉ lê bênh nhân không sốt chiếm tới $61,7 \%$.

Bảng 3. Đặc điểm vi khuẩn học.

\begin{tabular}{|c|c|c|c|}
\hline \multicolumn{2}{|c|}{ Kết quả nuôi cấy } & $\begin{array}{l}\text { Số } \\
\text { lương }\end{array}$ & Tỉ lệ\% \\
\hline \multicolumn{2}{|r|}{ Ãm tính } & 39 & 83 \\
\hline \multirow{5}{*}{$\begin{array}{l}\text { Dương } \\
\text { tính }\end{array}$} & E.coli & 4 & 8.6 \\
\hline & S.typhimurium & 1 & 2.1 \\
\hline & S.marcescens & 1 & 2.1 \\
\hline & K.pneumonia & 1 & 2.1 \\
\hline & S.aureus & 1 & 2.1 \\
\hline & Tống & 47 & 100 \\
\hline
\end{tabular}

Nhận xét: Tỉ lệ nuôi cấy được vi khuấn dương tính thấp chỉ có $17 \%$ tổng số ca bênh. Trong các vi khuẩn nuôi cấy được thì chủ yểu là vi khuẩn gram âm chiếm tới $87,5 \%$. 
Bảng 4. Đặc điểm lactat máu ở bệnh nhân sốc nhiếm khuẩn

\begin{tabular}{|c|c|c|}
\hline Lactat máu & Số lượng & Tỉ lệ(\%) \\
\hline$\leq 4$ & 15 & 31,9 \\
\hline $4,1-6$ & 8 & 17 \\
\hline$\geq 6$ & 24 & 51,1 \\
\hline Tống & $\mathbf{4 7}$ & $\mathbf{1 0 0} \%$ \\
\hline $\mathrm{X} \pm$ SD & \multicolumn{2}{|c|}{$6,82 \pm 4,16$} \\
\hline Min - Max & \multicolumn{2}{|c|}{$1,2-19,43$} \\
\hline
\end{tabular}

Nhận xét: Gía trị trung bình lactat máu của bệnh nhân sốc nhiễm khuẩn là $6,82 \pm 4,16$. Gía trị cao nhất là 19,43, thấp nhất là 1,2, Số bệnh nhân có lactat máu $\geq 6$ chiếm tî lệ cao nhất $51,1 \%$.

Bảng 3.5 Môí liên quan giữa thở máy, rôí loạn đồng máu và kêt cưc ra viện( $N=47)$

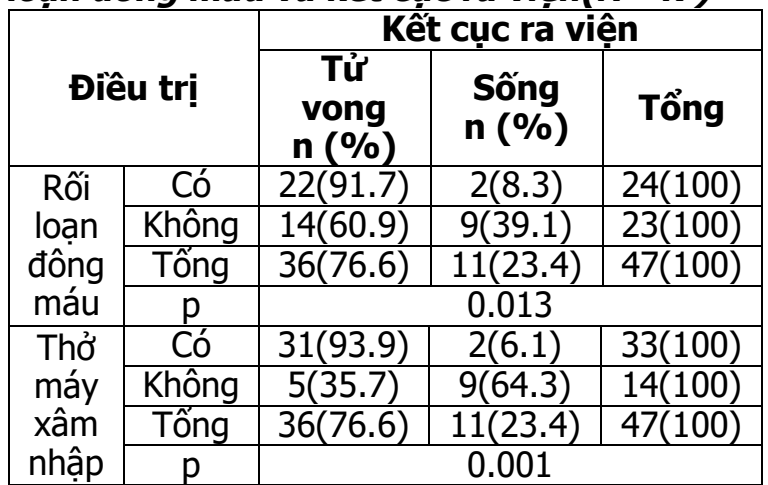

Nhân xét: - Bệnh thở máyxâm nhập có tỉ lệ tử vong cao hơn, có ý nghĩa thống kê với $p<0.05$.

- Bệnh nhân có rối loạn đông máu có tỉ lệ tử vong cao hơn, có ý nghĩa thống kê với $p<0.05$

\section{BÀN LUÂ̂N}

1. Bàn luận về đặc điểm lâm sàng của bệnh nhân sốc nhiễm khuẩn

Trong nghiên cứu của tôi, bệnh nhân sốc nhân sốc nhiễm khuẩn có tuổi trung bình của đối tượng nghiên cứu là $61,43 \pm 15,15$. Tuổi cao nhất là 92 và tuổi thấp nhất là 15 . Tuổi trung bình trong nghiên cứu của Phạm Quốc Dũng là $62,03 \pm 15,79[4]$, trong nghiên cứu Mai Văn Cường là 55,4 $\pm 18,3$ tuổi [8], Phạm Tuấn Đức là $55,9 \pm 15,8$ tuổi [5]

Tuổi càng cao sức đề kháng càng giảm,khả năng hồi phục chậm, thêm vào đó bệnh nhân có thể mắc một số bệnh mạn tính kèm theo, đây là yếu tố thuận lợi cho nhiễm khuẩn và tạo điều kiện cho nhiễm khuẩn tiến triển thành nhiễn khuẩn huyết biến chứng sốc nhiễm khuẩn

Tỉ lệ giới tính trong nghiên cứu của tôi nam chiếm tỷ lệ cao hơn $70,8 \%$, nữ chỉ chiếm $29,8 \%$. Tương đồng với các nghiên cứu của Phạm Tuấn Đức là 66,7\%[5]. Cao hơn tỉ lệ nam giới trong nghiên cứu của Phạm Quốc Dũng 41,9\%[4].
Sốt là triệu chứng thường gặp trên lâm sàng do những chất gây sốt có nguồn gốc từ bạch cầu đơn nhân và đại thực bào kích hoạt trung tâm gây sốt ở vùng dưới đồi. Khởi phát đột ngột thường do tình trạng nhiễm khuẩn. Có sự tương quan giữa nhiệt độ và độ nặng của bệnh. Triệu chứng sốt có thể không rõ ràng hoặc có thể không sốt bệnh nhân già hay bệnh nhân nhiễm khuẩn nặng nề. Trong nghiên cứu của tôi tî lệ bệnh nhân sốt cao là $23,4 \%$, sốt nhẹ là $34 \%$, không sốt chiếm cao nhất tới $42,6 \%$. Trong nghiên cứu của Pham Quốc Dũng[4] cũng chỉ có $22 \%$ bệnh nhân sốt cao. Điều này cho thấy trên lâm sàng đa số bệnh nhân dù sốc nhiễm khuẩn nhưng không có sốt và sốt nhe dễ gây bỏ sót ở bệnh nhân sốc nhiễm khuẩn.

Trong nghiên cứu của tôi, vị trí ổ nhiễm khuẩn tiên phát thường gặp là ở cơ quan hô hấp hoặc tiêu hóa.Trong đó hô hấp chiếm $44.7 \%$, tiêu hóa là 34\%, tiết niệu chỉ chiếm 6.4\%.Có 14.9\% bệnh nhân không rõ ổ nhiễm khuẩn tiên phát. Trong nghiên cứu của Phạm Quốc Dũng thì hô hấp chiếm $29,1 \%$, tiêu hóa chiếm $25,7 \%$, tiết niệu 16,1\%[4]. Trong nghiên cứu của Trần Minh Điểu thì vị trí ổ nhiễm khuẩn tiên phát hay gặp nhất là tiêu hóa chiếm $35,3 \%$, sau đó đến thần kinh chiếm 17,6\%, hô hấp chỉ chiếm 15,7\% [6], có sự khác biệt so với các nghiên cứu ở trên có thể do đối tượng nghiên cứu của Trân Minh Điểu là trẻ em.

\section{Bàn luận về đặc điểm cận lâm sàng} của bệnh nhẩn sốc nhiếm khuẩn

Trong nghiên cứu của tôi, tỉ lệ nuôi cấy dương tính chỉ có $17 \%$, trong đó chủ yếu là vi khuẩn gram âm chiếm tới $87,5 \%$. 50\% vi khuẩn gram âm là E.coli. Hiện nay trong những nguyên nhân sốc nhiễm khuẩn thì vi khuẩn gram âm ngày càng được ghi nhận là nguyên nhân chính. Trong nghiên cứu của Vũ Hải Yến tỉ lệ cấy máu dương tính là 21,6\% [3]. Trong nghiên cứu của Vincent tỉ lệ vi khuẩn gram âm là 62\%[9].

Gía trị trung bình lactat máu của bệnh nhân sốc nhiếm khuẩn là $6,82 \pm 4,16$. Số bểnh nhân có lactat máu $\geq 6$ chiếm tỉ lệ cao nhất 51,1 . Trong hầu hết các bệnh cảnh sốc, chỉ số lactat máu tăng phản ánh chuyển hóa yếm khí do giảm tưới máu, nhưng ở bệnh nhân sốc nhiễm khuẩn nồng độ lactat không luôn luôn đồng biến theo mức độ tưới máu. Tăng lactat máu là do giảm cung cấp oxy mô và rối loạn chuyển hóa tế bào. Mặc dù nồng độ lactate máu không được xem là đại diện cho thiếu oxy mô nhưng tăng nồng độ lactate máu có giá trị chẩn đoán và giá trị tiên lượng ở bệnh nhân sốc nhiễm khuẩn[2] 


\section{Bàn luận về yếu tố liên quan đến kết quả điều trị \\ - Bệnh nhân có rối loạn đông máu có tỉ lệ tử} vong cao hơn có ý nghĩa thống kê với $\mathrm{p}<0,05$. Các xét nghiêm đánh giá tình trang đông máu giúp đánh giá, tiên lượng bệnh cũng như kếtquả điêu trị, hỗ trợ có một cái nhìn đúng về tình mức đô bênh và can thiệp chữa trị kịp thời[1]. Nghiên cứu của tôi cũng tương tự như của Tseng và cộng sự vào năm 2007 cho thấy những bệnh nhân có rối loạn đông máu có nguy cơ tử vong cao có ý nghĩa thống kê với $p<0,05[7]$

- Bệnh nhân thở máy có tỉ lệ tử vong cao hơn có ý nghĩa thống kê với $p<0,05$. Bệnh nhân sốc nhiểm khuẩn thường có tình trạng suy hô hấp từ trước và cần hố trợ hô hấp khi nhập viện. Bệnh nhân cần thở máy xâm nhập là bệnh nhân có tình trạng rối loạn hô hấp, rối loạn ý thức, rối loạn huyết động nặng nề, cùng với đó là những nguy cơ do thở máy như nhiễm khuẩn thứ phát, nhiễm khuẩn bệnh viện làm tăng nguy cơ tử vong của bệnh nhân

\section{KẾT LUẬN}

Nghiên cứu trên 47 bênh nhân sốc nhiễm khuẩn điều trị tại bệnh viện Trung ương Thái Nguyên từ tháng 7 năm 2019 đến tháng 7 năm 2020. Tôi có một số kết luận sau:

- Bênh nhân tuổi càng cao càng có nguy cơ sốc nhiễm khuẩn cao hơn.

- Nam giới có tỉ lệ mắc bệnh cao hơn nữ giới.

- Ổ nhiếm khuẩn tiên phát thường gặp nhất là cơ quan hô hấp

- Tỉ lệ cấy máu dương tính thấp. Chủ yếu là vi khuẩn gram âm.

- Có mối liên quan có ý nghĩa thống kê với độ tin cậy 95\% giữa tình trạng rối loạn đông máu, thở máy xâm nhập và kết cục ra viện ở bệnh nhân sốc nhiễm khuẩn.

TÀI LIỆU THAM KHẢO

1. Angus DC. L-ZW, Lidicker J. et al (2001). "Epidemiology of severe sepsis in the unite States: analysis of incidence, outcome, and associated cost of care", Crit Care Med, 29, pp.1303-1310, pp.

2. Chertoff J. CM, Garcia B., et al (2015). Lactate kinetics in sepsis and septic shock: a review of the literature and rationale for further research. J Intensive Care, 3(39), 1-4, pp.

3. Vũ Hải Yến (2012). Nghiên cứu đăc điểm lâm sàng- cận lâm sàng và kểt quả của liệuu pháp điều tri sớm theo muc tiêu ở bệnh nhân sốc nhiếm khuẩn. Luận văn thạc sỹ y học, Trường Đại học Y Hà Nô̂i. Tr 34-55.

4. Phạm Quốc Dũng LTVH, Nguyễn Mạnh Dũng (2019), "Đặc điểm lâm sàng, cận lâm sàng và nồng độ môt số cytokine ở bệnh nhân sốc nhiếm khuẩn", Tạp chí Y Dược lâm sàng 108. Tâp 14 - số 4, pp.

5. Pham Tuấn Đức (2011). Đánh giá thay đổi vân chuyển ôxy và tiêu thụ ôxy trên bệnh nhân sốc nhiểm khuẩn. Luân văn thạc sỹ y học $T Ð$, pp.

6. Trân Minh Điến (2010). Nghiên cứu kết quả điều trị và một số yếu tố tiên lượng tứ vong trong sốc nhiễm khuẩn trẻ em. Luânn án tiến sỹ $Y$ học. Trường Đai hoc Y Hà Nôii. Tr 55-87

7. Tseng YC. WJ, Wu FLL. et al. (2007), "Prognosis of adult patients with bacteremia caused by extensively resistant Acinetobacter baumannii", Diagnostic Microbiology and Infectious Disease, 59, pp.181-190, pp.

8. Mai Vắn Cường (2011). Nghiên cứu sự liên quan giữa áp lực tĩnh mach trung tâm và áp lực mao mạch phổi bít ở bệnh nhân sốc nhiếm khuẩn và sốc tim. Luận văn tốt nghiệp bác sĩ nội trú bệnh viện. Trường Đại học Y Hà Nội. Tr 29-53.

9. Vincent $J L$ SY, Sprung $C L$, Ranieri VM, Reinhart K, Gerlach H, Moreno R, Carlet J, Le Gall JR, Payen D (2006). Sepsis Occurrence in Acutely Ill Patients Investigators. Sepsis in European intensive care units: results of the SOAP study. Crit Care Med. 34:344-53, pp.

\section{CHẤT LƯợNG CUỘC SỐNG CỦA NGƯờI BÊNH UNG THƯ VÚ VÀ MộT Số YẾU TỐ LIÊN QUAN TẠI BỆNH VIỆN ĐA KHOA KIÊN GIANG, NĂM 2020}

\section{TÓM TẮT.}

\author{
${ }^{1}$ Trường ĐH Thăng Long \\ ${ }^{2}$ Bênh viên $Đ K$ Kiên Giang \\ Chịu trách nhiệm chính: Nguyễn Phi Hải \\ Email: nguyenphihai@gmail.com \\ Ngày nhận bài: 23.10.2020 \\ Ngày phản biện khoa học: 30.11 .2020 \\ Ngày duyệt bài: 10.12.2020
}

\section{Nguyễn Phi Hải ${ }^{1,2}$, Bùi Hoài Nam ${ }^{1}$}

Nghiên cứu mô tả cắt ngang thực hiện trên 138 người bênh taii bênh viên đa khoa Kiên Giang từ tháng 01/2020 đến 6/2020 trên bệnh nhân ung thư vú. Mục tiêu làm ô tả đặc điểm lâm sàng, cận lâm sàng của người bệnh ung thư vú. Phân tích chất lượng cuộc sống liên quan đến điều trị, chăm sóc và một số yểu tố liên quan khác. Số liệu thu thập được là bảng theo dõi điêu dưỡng chăm sóc bênh nhân như tỷ lệnữ cao hơn nam, tỷ lẹ cao nhất ở nhóm tuổi $40-59$ tuổi (68.8\%), tiếp đ̛ến nhóm tuổi $>=60$ tuổi $(27.5 \%)$, tỷ lệ thấp nhất thuộc nhóm tuổi <=39 tuổi (3.6\%). Tỳ lệ 